\title{
Short-term variations in oscillatory and spirometric lung function indices among school children
}

\author{
K.L. Timonen*, J.T. Randell**, R.O. Salonen**, J. Pekkanen*
}

Short-term variations in oscillatory and spirometric lung function indices among school children. K.L. Timonen, J.T. Randell, R.O. Salonen, J. Pekkanen. (CERS Journals Ltd 1997.

ABSTRACT: The aim of this study was to compare immediate, daily and weekly variation in respiratory resistance measured by means of the forced oscillation technique ( $R$ rs,FOT) to spirometric indices in 7-12 year old children with chronic respiratory symptoms.

The lung function measurements were performed in 19 children on 4 days, i.e. two consecutive days during two consecutive weeks. On each day, the measurements were carried out at the same time of day and always repeated three times. In addition, $R$ rs,FOT and spirometric lung function indices were compared with an exercise challenge test in 12 children.

Intrasubject coefficients of variation (CoVs) for Rrs,FOT were larger than those for spirometric indices. Only in the immediately repeated measurements was the CoV of maximal expiratory flow at $25 \%$ vital capacity larger than that of $R$ rs,FOT $(16.6$ vs $14.9 \%)$. At all time intervals, the smallest CoVs were observed in forced vital capacity (FVC) or in the ratio of forced expiratory volume in one second to FVC (2.0-2.6\%). When excluding Rrs,FOT values which were not within 2 SD $(0.11$ $\left.\mathrm{kPa} \cdot \mathrm{L}^{-1} \cdot \mathrm{s}\right)$ of the differences between the immediately repeated measurements, the $\mathrm{CoV}$ of the immediately repeated measurements of $\mathrm{Rrs}$,FOT was reduced to $9.1 \%$, being smaller than that of maximal mid-expiratory flow $(\mathbf{1 0 . 1 \% )}$. However, even then the day-to-day variation in $R$ rs,FOT was clearly larger $(16.0 \%)$ than those of the airflow indices at specified lung volumes $(7.2-8.3 \%)$. This was also true for the weekly variation. In the exercise challenge test, there were larger changes in $R$ rs,FOT values than in the spirometric indices, but $R$ rs,FOT was the most sensitive index to detect changes in the respiratory system.

In conclusion, the variation in $R$ rs,FOT values was larger than that of most spirometric indices. When a reliability index was applied, the immediate variation in $R$ rs,FOT values was comparable to those of the airflow indices at specified lung volumes. $R$ rs,FOT was also the most sensitive index in the exercise challenge test, and therefore it seems to be suitable for detection of short-term functional changes in the respiratory system. However, the relatively low repeatability of $R$ rs,FOT over days and weeks may limit its applicability to longer-term follow-ups. Eur Respir J., 1997; 10: 82-87.
Units of *Environmental Epidemiology and **Toxicology

Division of Environmental Health

National Public Health Institute

Kuopio

Finland

Correspondence: K. Timonen

National Public Health Institute

Unit of Environmental Epidemiology

P.O. Box 95

FIN-70701 Kuopio

Finland

Keywords: Asthmatic children

lung function

oscillatory resistance

spirometry

variability

\section{Received: December 71995}

Accepted after revision August 201996
Spirometry is a conventional and well-documented method for detecting lung function changes. However, there are some difficulties in spirometric lung function measurements, especially in children. Spirometry needs good active co-operation, and at the beginning of the forced expiration, in particular, the correct breathing technique is required. The end of the forced expiration does not depend on the force developed by the expiratory muscles, but children tend to finish the expiration too early. As a result of the incomplete expiratory effort there can be a large overestimation of maximal expiratory flow at $25 \%$ vital capacity (MEF25) [1]. In addition, the forced breathing manoeuvre may affect bronchomotor tone $[1,2]$.

Lung function measurement by the forced oscillation technique (FOT) is easy to perform [3]. It needs only passive co-operation, as no special breathing manoeuvres are needed. In addition, as the measurements are performed during tidal breathing, the bronchomotor tone is not affected. FOT has been successfully used in neonates [4], children [5-8] and even during anaesthesia $[9,10]$. Nowadays, the equipment is also compact in size and suitable for field studies. However, there are several types of device in use, and the validation of the method and of different devices is not yet complete.

The aim of the first part of this study was to compare respiratory resistance recorded using FOT $(R \mathrm{rs}, \mathrm{FOT})$ to spirometric lung function indices with regard to immediate, day-to-day and week-to-week variations, in primary school children with chronic respiratory symptoms. In the second part of the study, the two methods were compared in an exercise challenge test. 


\section{Subjects and methods}

\section{Subjects}

In February 1993, chronic respiratory symptoms were screened by a parent-completed questionnaire in a primary school in Siilinjärvi, Finland. The symptoms that were asked about included "wheezing during the last 12 months"; "attacks of shortness of breath with wheezing during the last 12 months"; "almost daily cough during day or night for three consecutive months"; and "doctordiagnosed asthma".

At the end of April 1993, 29 children with chronic respiratory symptoms were asked to participate in this study, and $24(83 \%)$ agreed. A total of $19(79 \%)$ children (11 girls and 8 boys, mean (SD) age 9.9 (1.4) yrs (range 7-12 yrs) height $142(13) \mathrm{cm}(120-160 \mathrm{~cm})$, weight 40 (13) $\mathrm{kg}(23-62 \mathrm{~kg})$ ) attended all the measurements. Fifteen children had suffered from wheezing, seven from shortness of breath with wheezing, and 10 had suffered from daily cough. Eight children had doctor-diagnosed asthma. Ten children used daily medication for respiratory symptoms, and they were asked to take their medication as usual.

Written consent was obtained from all the parents of the children before the measurements. The study protocol was approved by the Ethics Committee of the Kuopio University Hospital and the University of Kuopio.

\section{Study design}

In the first part of the study, the lung function measurements were performed in the same children, and always at the same time on 4 days, i.e. on two consecutive days during two consecutive weeks. A week before the study, the subjects were familiarized with the equipment and the test procedure. During each visit, three recordings of $R \mathrm{rs}$,FOT were made without applying any acceptance criteria, followed by three acceptable spirometric measurements. In the second part of the study, 12 children ( 5 boys and 7 girls) participated once in an exercise challenge test inside the school. The subjects were randomly selected from the 19 children who volunteered to continue in this study. Before the exercise test, and 2 and $10 \mathrm{~min}$ after the test, two acceptable recordings of $R$ rs,FOT were obtained, followed by two acceptable recordings of spirometric lung function indices. In Rrs,FOT measurements, two consecutive recordings were regarded as acceptable, if the difference between the values was $\leq 0.11 \mathrm{kPa} \cdot \mathrm{L}^{-1} \cdot \mathrm{s}$, i.e. 2 times SD of the differences between the first and second immediately repeated measurements obtained in the first part of the study.

\section{Lung function measurements}

$R$ rs,FOT was recorded using the Custo Vit ${ }^{\mathrm{TM}}$ directreading resistance meter (Custo Med, Munich, Germany). An input pressure signal was applied at the mouth using a frequency of $8 \mathrm{~Hz}$. The subjects were seated with the nose clipped, and the neck extended backwards. To reduce artefact from the upper airways, the subjects supported the mouth and cheeks with one hand [11], while the other hand supported the handpiece of the resistance meter. After about 30-45 s of tidal breathing through the mouthpiece, there was a $15 \mathrm{~s}$ sampling of the flow and pressure signals for analysis. The Rrs,FOT value was automatically calculated as the average resistance value from the pressure-flow curves [12] having the lowest phase angle between the inspiratory and expiratory phases. The input frequency of $8 \mathrm{~Hz}$ was chosen from the available frequencies of 8,12 and $16 \mathrm{~Hz}$, because it had produced the best correlation between the Rrs,FOT measured with the Custo Vit device and the airway resistance measured with the body plethysmograph [13]. Furthermore, forced oscillation variables should be recorded at low oscillation frequencies in order to minimize the upper airways shunt [14].

Spirometric flow-volume curves were recorded with a heated Fleisch-type pneumotachograph (Medikro M 5530 ${ }^{\mathrm{TM}}$ No. 3; Medikro Oy, Kuopio, Finland), which was connected to a computerized spirometer (Medikro101 ${ }^{\mathrm{TM}}$; Medikro Oy, Kuopio, Finland). The subjects were seated and wore a noseclip. The measurements were carried out according to the recommendations of the European Respiratory Society [1]. The curves were accepted if the values of forced vital capacity (FVC) were within $5 \%$ or $100 \mathrm{~mL}$ of each other, whichever was greater. In addition to FVC, the following lung function parameters were derived from the curves: forced expiratory volume in one second (FEV1), $\mathrm{FEV} 1 / \mathrm{FVC}$ ratio, peak expiratory flow (PEF), maximal expiratory flow at $50 \%$ and $25 \%$ vital capacity (MEF50 and MEF25), maximal mid-expiratory flow (MMEF), and the area under the flow-volume curve (AFV). The resistance meter and the spirometer were calibrated for volume with a $3 \mathrm{~L}$ syringe. The calibrations were performed every morning before the measurements. All lung function measurements were carried out indoors at school between 10:00 and 14:30 h during May 1993, and the results were corrected to body temperature, atmospheric pressure and saturation with water vapour (BTPS).

\section{Exercise challenge test}

The exercise challenge test lasted $8 \mathrm{~min}$. The children exercised using a bicycle ergometer (Monark 818E; Ergomedic, Varberg, Sweden). During the test, the nose was clipped, and the cardiac frequency was monitored with a Sport Tester heart rate meter (Polar Electro; Kempele, Finland). The target work load was $75-80 \%$ of the maximum cardiac frequency, calculated from the equation $205-(1 / 2 \times$ age $)$. For the first minute, the work load was set to $60 \%$ of the target load. It was increased to $75 \%$ in the second minute, $90 \%$ in the third minute, and $100 \%$ in the fourth minute; and was then maintained for the remaining $4 \mathrm{~min}$ [15].

\section{Pollen data}

During the whole month, there were exceptionally high levels of birch pollen in outdoor air. 
The data on pollen counts were obtained from the Finnish Aerobiology Group. The measurement site was located in Kuopio, at $25 \mathrm{~km}$ from the study area. The mean total pollen count during the week preceding the first part of the study was 4,215 pollen grains $\cdot \mathrm{m}^{-3}$ (range 1,516-7,344 pollen grains $\cdot \mathrm{m}^{-3}$ ), and 3,781 pollen grains $\cdot \mathrm{m}^{-3}$ during the two study days of the first week. During the two study days of the second week, the mean count was 429 pollen grains. $\mathrm{m}^{-3}$, and between the study days of the first and second week the mean count was 1,185 pollen grains $\cdot \mathrm{m}^{-3}$ (range $824-1,973$ pollen grains $\cdot \mathrm{m}^{-3}$ ). During the days when the exercise challenge tests were performed, the mean total pollen count was 61 pollen grains $\cdot \mathrm{m}^{-3}$.

\section{Data analysis}

The variation in lung function measurements can be divided into "within-subject" variation and "betweensubject" variation. In the present study, "within-subject" variation can be due to changes in lung function over the three repeated measurements, over the day, or over the week. All these different components of the total variance of each lung function parameter can be estimated using analyses of variance (ANOVA). When the design is completely nested, as in the present study, this estimation can conveniently and efficiently be made using a random effects ANOVA with a nested structure (PROC NESTED in Statistical Analysis System (SAS)) [16].

Coefficient of intrasubject variation $(\mathrm{CoV})$ is another way to describe within-subject variation. $\mathrm{CoV}$ is calculated as the standard deviation of the differences between the repeated measurements in the same subject divided by the mean value of all measurements, and it was calculated for immediate, day-to-day and week-toweek variation [17]. To get the $\mathrm{CoV}$ of immediate variation, the CoV between the first and second, the first and third, and the second and third recordings were averaged. In calculations of the coefficient of day-to-day variation, the average values of the first and third study days were compared to the average values of the sec- ond and fourth study days. Similarly, the average values of the first and second study days were compared to average values of the third and fourth study days to get the coefficient of week-to-week variation.

In the Rrs,FOT data, analyses were also performed by applying a reliability index to the immediately repeated measurements, i.e. excluding the values that differed from each other by more than $0.11 \mathrm{kPa} \cdot \mathrm{L}^{-1} \cdot \mathrm{s}$ (two times SD of the difference between repeated measurements). Differences between means were tested with analysis of variance (PROC GLM (general linear models) in SAS) [16].

For additional comparison and to estimate the sensitivity of different lung function parameters to detect changes in the respiratory system, the $\mathrm{CoV}$ was compared to the maximal relative change in the respective lung function indices after the exercise test. The $\mathrm{CoV}$ values were calculated from the baseline values of $R$ rs,FOT, FVC, FEV1, MMEF and AFV in the exercise test, because the reliability index was applied on the spot to the immediately repeated $R$ rs,FOT measurements of the second part of the study. The changes in the lung function indices were calculated using the mean value of the two immediately repeated $R$ rs,FOT measurements and the spirometric flow-volume curve with the largest FVC value. The measurements at 2 and $10 \mathrm{~min}$ after the exercise test were compared to the baseline measurements before the exercise, and the largest difference between the baseline value and the values measured after the test was included in the analyses as the maximal change. The maximal relative change was calculated by dividing this difference by the baseline value.

\section{Results}

There were no statistically significant differences in the mean values of $R$ rs,FOT and spirometric indices between the four study days (table 1), or between the three immediately repeated measurements on the same day (table 2). The FVC, FEV1 and MMEF values were 97\%, $91 \%$ and $82 \%$ of the predicted values for Finnish children, respectively.

Table 1. - Lung function indices on two consecutive days in two consecutive weeks

\begin{tabular}{|c|c|c|c|c|}
\hline \multirow[b]{2}{*}{ Indices } & \multicolumn{2}{|c|}{ Week 1} & \multicolumn{2}{|c|}{ Week 2} \\
\hline & $\begin{array}{c}\text { Day 1 } \\
(\mathrm{n}=57)^{*}\end{array}$ & $\begin{array}{c}\text { Day } 2 \\
(\mathrm{n}=57)\end{array}$ & $\begin{array}{l}\text { Day } 3 \\
(\mathrm{n}=57)\end{array}$ & $\begin{array}{l}\text { Day } 4 \\
(n=57)\end{array}$ \\
\hline$R_{\mathrm{rs}, \mathrm{FOT}} \mathrm{kPa} \cdot \mathrm{L}^{-1} \cdot \mathrm{s}$ & $0.55(0.18)$ & $0.52(0.16)$ & $0.55(0.19)$ & $0.53(0.13)$ \\
\hline FVC L & $2.47(0.52)$ & $2.46(0.52)$ & $2.46(0.57)$ & $2.42(0.53)$ \\
\hline FEV1 L & $2.07(0.45)$ & $2.08(0.41)$ & $2.07(0.45)$ & $2.04(0.45)$ \\
\hline FEV1/FVC \% & $84(10)$ & $85(8)$ & $85(8)$ & $85(9)$ \\
\hline $\mathrm{PEF} \quad \mathrm{L} \cdot \mathrm{s}^{-1}$ & $4.36(0.95)$ & $4.43(0.97)$ & $4.34(1.07)$ & $4.23(0.99)$ \\
\hline MEF50 L $\cdot \mathrm{s}^{-1}$ & $2.51(0.90)$ & $2.47(0.76)$ & $2.44(0.80)$ & $2.48(0.81)$ \\
\hline MEF25 L $\mathrm{L} \cdot \mathrm{s}^{-1}$ & $1.11(0.50)$ & $1.12(0.57)$ & $1.16(0.51)$ & $1.11(0.55)$ \\
\hline MMEF $\mathrm{L} \cdot \mathrm{s}^{-1}$ & $2.23(0.79)$ & $2.20(0.71)$ & $2.24(0.77)$ & $2.22(0.81)$ \\
\hline $\mathrm{AFV} \mathrm{L} \mathrm{L}^{2} \cdot \mathrm{s}^{-1}$ & $5.80(2.34)$ & $5.82(2.06)$ & $5.81(2.42)$ & $5.62(2.25)$ \\
\hline
\end{tabular}

On each day, three immediately repeated measurements of $R \mathrm{rs}$,FOT and spirometric lung function indices were performed in 19 children. Values are presented as mean, and SD in parenthesis. *: n=number of values measured. Rrs,FOT: resistance of the respiratory system measured by the forced oscillation technique; FVC: forced vital capacity; FEV1: forced expiratory volume in one second; PEF: peak expiratory flow; MEF50 and MEF25: maximal expiratory flow at 50 and 25\% vital capacity, respectively; MMEF: maximal mid-expiratory flow; AFV: area under the flow-volume curve. 
Table 2. - Lung function indices in three immediately repeated measurements in 19 children on two consecutive days during two consecutive weeks

\begin{tabular}{|c|c|c|c|}
\hline \multirow[b]{2}{*}{ Parameter } & \multicolumn{3}{|c|}{ Measurement } \\
\hline & $\begin{array}{c}1 \\
(\mathrm{n}=76)^{*}\end{array}$ & $\begin{array}{c}2 \\
(n=76)\end{array}$ & $\begin{array}{c}3 \\
(\mathrm{n}=76)\end{array}$ \\
\hline$R \mathrm{rs}, \mathrm{FOT} \quad \mathrm{kPa} \cdot \mathrm{L}^{-1} \cdot \mathrm{s}$ & $0.53(0.17)$ & $0.54(0.17)$ & $0.56(0.16)$ \\
\hline FVC L & $2.45(0.54)$ & $2.45(0.53)$ & $2.45(0.53)$ \\
\hline FEV1 L & $2.06(0.43)$ & $2.06(0.43)$ & $2.06(0.45)$ \\
\hline FEV1/FVC \% & $85(8)$ & $85(8)$ & $85(9)$ \\
\hline $\mathrm{PEF} \quad \mathrm{L} \cdot \mathrm{s}^{-1}$ & $4.35(0.98)$ & $4.31(0.99)$ & $4.39(1.01)$ \\
\hline MEF50 $\mathrm{L} \cdot \mathrm{s}^{-1}$ & $2.47(0.81)$ & $2.48(0.81)$ & $2.46(0.84)$ \\
\hline MEF25 L L $\cdot \mathrm{s}^{-1}$ & $1.12(0.49)$ & $1.11(0.54)$ & $1.15(0.57)$ \\
\hline MMEF $\quad \mathrm{L} \cdot \mathrm{s}^{-1}$ & $2.23(0.74)$ & $2.22(0.75)$ & $2.21(0.81)$ \\
\hline AFV $\quad L^{2} \cdot s^{-1}$ & $5.76(2.25)$ & $5.75(2.24)$ & $5.78(2.31)$ \\
\hline
\end{tabular}

Values are presented as mean, and SD in parenthesis. *: $\mathrm{n}=$ number of values measured. For definitions see legend to table 1 .

In spirometric lung function measurements, the "betweensubjects" variation was the largest component of variance (table 3). In Rrs,FOT measurements, the proportions both of "within-subject between days" and "within-subject between immediately repeated measurements" variation were much larger than in spirometric measurements. The proportion of "within-subject between weeks" variation was small in all lung function indices. When the reliability index of $0.11 \mathrm{kPa} \cdot \mathrm{L}^{-1} \cdot \mathrm{s}$ was applied to control the quality of the Rrs,FOT data, 31 (14\%) values were discarded. This decreased the proportion of the "withinsubject between immediately repeated measurements" variation in the total variance from $23.8 \%$ to $6.6 \%$, but it had little effect on the "between subjects" variation.

The CoV of immediate variation in Rrs,FOT (14.9\%) was larger than that in all spirometric parameters with the exception of MEF25 (16.6\%) (table 4). With regard to day-to-day and week-to-week variation, the $\mathrm{CoV}$ was largest in Rrs,FOT. FVC, FEV1 and FEV1/FVC had the smallest $\mathrm{CoV}$ values at all time intervals. When $31 R \mathrm{rs}$,FOT values exceeding the reliability index were excluded, the $\mathrm{CoV}$ of immediate variation decreased to $9.1 \%$. When

Table 3. - The proportions of different components in the total variance of lung function indices

\begin{tabular}{lcccc}
\hline & & \multicolumn{3}{c}{ Within subjects } \\
\cline { 3 - 5 } & $\begin{array}{c}\text { Between- } \\
\text { subjects }\end{array}$ & $\begin{array}{c}\text { Between- } \\
\text { weeks }\end{array}$ & $\begin{array}{c}\text { Between- } \\
\text { days }\end{array}$ & $\begin{array}{c}\text { Between } \\
\text { immediately } \\
\text { repeated } \\
\text { measurements }\end{array}$ \\
\hline Rrs,FOT & 46 & 1.2 & 29.3 & 23.8 \\
Rrs,FOT'\# & 43 & 0.0 & 50.1 & 6.6 \\
FVC & 96 & 1.7 & 1.1 & 1.4 \\
FEV1 & 92 & 2.6 & 3.4 & 2.2 \\
FEV1/FVC $\%$ & 84 & 0.4 & 8.6 & 7.3 \\
PEF & 83 & 3.6 & 4.8 & 8.4 \\
MEF50 & 89 & 1.0 & 4.7 & 5.0 \\
MEF25 & 82 & 3.8 & 2.6 & 11.9 \\
MMEF & 86 & 3.7 & 2.3 & 8.2 \\
AFV & 92 & 1.9 & 2.6 & 3.3 \\
\hline
\end{tabular}

\#: 31 values exceeding 2 times SD $\left(0.11 \mathrm{kPa} \cdot \mathrm{L}^{-1} \cdot \mathrm{s}\right)$ of the difference between immediately repeated measurements were excluded. For definitions see legend to table 1.
Table 4. - Coefficients of intrasubject variation (CoV $\%$ ) in Rrs,FOT and spirometric indices at various measurement intervals

\begin{tabular}{lccc}
\hline Indices & $\begin{array}{c}\text { Immediate } \\
(\mathrm{n}=228)^{*} \\
\text { CoV \% }\end{array}$ & $\begin{array}{c}\text { Day-to-day } \\
(\mathrm{n}=38) \\
\mathrm{CoV} \%\end{array}$ & $\begin{array}{c}\text { Week-to-week } \\
(\mathrm{n}=38) \\
\mathrm{CoV} \%\end{array}$ \\
\hline$R_{\mathrm{rs}, \mathrm{FOT}}$ & 14.9 & 11.4 & 14.0 \\
$R_{\mathrm{rs}, \mathrm{FOT}}{ }^{\prime}$ & 9.1 & 16.0 & 13.2 \\
FVC & 2.6 & 2.0 & 3.5 \\
FEV1 & 3.2 & 3.0 & 4.7 \\
FEV1/FVC & 2.8 & 2.2 & 2.5 \\
PEF & 6.7 & 4.2 & 6.3 \\
MEF50 & 7.5 & 7.2 & 6.4 \\
MEF25 & 16.6 & 8.1 & 12.8 \\
MMEF & 10.1 & 8.3 & 8.8 \\
AFV & 7.2 & 5.2 & 7.7 \\
\hline
\end{tabular}

Three immediately repeated measures were performed in 19 children on two consecutive days during two consecutive weeks. *: $n=$ number of values in analysis. \#: 31 values exceeding 2 SD $\left(0.11 \mathrm{kPa} \cdot \mathrm{L}^{-1} \cdot \mathrm{s}\right)$ of the difference between the immediately repeated measurements were excluded. For definitions see legend to table 1 .

calculating the $\mathrm{CoV}$ of day-to-day variation in $R \mathrm{rs}, \mathrm{FOT}$ separately for the first and second weeks and applying the reliability index, the CoV was $26.3 \%$ in the first week and $12.3 \%$ in the second week.

At the end of the exercise challenge test, the mean (range) cardiac frequency was 167 (163-171) beats. $\mathrm{min}^{-1}$ and the mean (range) workload 72 (40-120) W. In lung function, the largest relative changes occurred in $R$ rs,FOT and MMEF values (table 5). The Pearson correlation coefficients between the relative changes in $R$ rs,FOT and spirometric indices were 0.12 for FVC, -0.41 for FEV1, -0.43 for MMEF, and -0.52 for AFV, and none of them was statistically significant. When the mean of the maximal relative changes was divided by the respective $\mathrm{CoV}$ of immediate variation to compare the sensitivity of the parameters, the highest ratio (1.8) was found in $R$ rs,FOT and the lowest in FVC (0.6). The ratios for the other spirometric parameters (FEV1, MMEF, AFV) were close to one.

\section{Discussion}

Lung function measurements with FOT are attractive, because the measurements are performed during tidal breathing and they need only passive co-operation from the subject. When using FOT, the bronchial tone is not affected, as may happen during forced breathing manoeuvres $[1,2]$. However, the methodology of FOT is not yet completely validated. We compared oscillatory respiratory resistance measured at a fixed $8 \mathrm{~Hz}$ frequency to spirometric indices in primary school children with chronic respiratory symptoms. The comparison included time intervals relevant to clinical and epidemiological follow-up studies.

In the present study, the variation of Rrs,FOT was larger than that of the spirometric indices. In immediately repeated measurements, only MEF25 was less repeatable than Rrs,FOT. FVC and FEV1 were highly repeatable. With regard to day-to-day and week-to-week variation, $R$ rs,FOT varied most, but the repeatability was 
Table 5. - Lung mechanics in the exercise challenge tests conducted in 12 children

\begin{tabular}{|c|c|c|c|c|c|}
\hline Indices & Baseline values ${ }^{\#}$ & $\begin{array}{c}\mathrm{CoV} \\
\%\end{array}$ & & $\begin{array}{c}\operatorname{Max} \Delta^{\ddagger} \\
\%\end{array}$ & $\begin{array}{c}\operatorname{Max} \Delta / \mathrm{CoV} \\
\%\end{array}$ \\
\hline$R \mathrm{rs}, \mathrm{FOT} \quad \mathrm{kPa} \cdot \mathrm{L}^{-1} \cdot \mathrm{s}$ & $0.54(0.16)$ & 6.7 & 12.0 & $(26.6 ;-23-74)$ & 1.8 \\
\hline FVC L & $2.56(0.53)$ & 2.7 & -1.6 & $(3.5 ;-11-2.0)$ & 0.6 \\
\hline FEV1 L & $2.16(0.40)$ & 3.7 & $-3.4^{*}$ & $(3.5 ;-11-15)$ & 0.9 \\
\hline MMEF $\quad \mathrm{L} \cdot \mathrm{s}^{-1}$ & $2.41(0.88)$ & 9.8 & $-10.1^{*}$ & $(8.1 ;-27-1.9)$ & 1.0 \\
\hline $\mathrm{AFV} \quad \mathrm{L}^{2} \cdot \mathrm{s}^{-1}$ & $6.30(2.72)$ & 6.9 & $-8.2^{*}$ & $(5.8 ;-22-0)$ & 1.2 \\
\hline
\end{tabular}

\#: mean, and SD in parenthesis; $¥$ : mean value, and SD and range in parenthesis. CoV: coefficient of intrasubject variation for the two immediately repeated baseline measurements before exercise; Max $\Delta$ : $\operatorname{maximal}$ relative change in the exercise challenge test. For further definitions see legend to table $1 . *: \mathrm{p}<0.05$, significance of the difference between the baseline value and the value after exercise.

comparable to MEF25 and MMEF, which have been reported to be sensitive indicators of airway obstruction [18]. Although it would be desirable to have a measurement that was both highly sensitive and highly repeatable, a reasonable balance has to be found between the two.

The mean values of $R$ rs,FOT and spirometric indices did not vary significantly between the three immediately repeated measurements. However, the standard deviations of nearly all spirometric parameters were larger in the second and third measurements than in the first measurement, suggesting that the forced breathing manoeuvre affected bronchomotor tone, especially in smaller airways [2].

With regard to immediate repeatability of $R$ rs,FOT, our results are in agreement with previous studies. In the study by DUIVERMAN et al. [6], FOT was compared to the expiratory flow-volume curves in asthmatic children. The $\mathrm{CoV}$ of the immediate variation in respiratory resistance measured at $6 \mathrm{~Hz}$ was $11.1 \%$, and those in FEV1 and MEF25 were $4.2 \%$ and $11.2 \%$ respectively. LÀNDSÉR et al. [19] reported that the average CoV of respiratory resistance measured by multiple frequency oscillometry was $11 \%$ in healthy children. In a study by LEBECQUE and co-workers [20], a mean value of $9.3 \%$ was reported for individual $\mathrm{CoV}$ of respiratory resistance measured at $6 \mathrm{~Hz}$ in children who had respiratory symptoms. In a further study by LEBECQUE and co-workers [21] in healthy children, the respiratory resistance was measured at $10 \mathrm{~Hz}$, and the spirometric flow-volume curves were also recorded. Based on the three best manoeuvres, the intraindividual $\mathrm{CoV}$ was less than $5 \%$ in respiratory resistance, less than $7 \%$ in MMEF, and less than $2 \%$ in FVC and FEV1. Holmgren et al. [22] reported an intraindividual variability of $7.5 \%$ in the inspiratory resistance measured at $4 \mathrm{~Hz}$ in asthmatic children. In addition, a $\mathrm{CoV}$ of $12 \%$ was reported by SOLYMAR et al. [23] for the respiratory resistance in asthmatic children, and a $\mathrm{CoV}$ of $11.2 \%$ was reported by WILSON et al. [24] in 5 year old wheezy children.

There is less literature concerning day-to-day and weekto-week repeatability in respiratory resistance values. GIMENO et al. [25] studied changes in respiratory resistance and FEV1 over several days, and the CoV of respiratory resistance was $10.8 \%$ in healthy adults, and $14.4 \%$ and $17.0 \%$ in patients with chronic obstructive pulmonary disease (COPD) at ages under and over 55 yrs, respectively. The CoV of FEV1 was $2.2 \%$ in healthy subjects and 10.4-11.7\% in patients with COPD. These findings are in good agreement with the present results in symptomatic children.
There is a lack of objective control over the breathing technique in $R$ rs,FOT measurements, and it has, therefore, been recommended that some reliability index should be used [11]. We applied a simple index of \pm 2 times SD of the differences between immediately repeated measurements to control the quality of the data collected. This lowered the $\mathrm{CoV}$ of immediately repeated measurements to $9.1 \%$, which was then similar to the $\mathrm{CoV}$ values of MMEF and MEF50, but still clearly higher than those of FVC, FEV1, and FEV1/FVC. The deviating values in $R$ rs,FOT that were excluded could be due to artefacts made consciously or subconsciously by the subjects, e.g. by holding their breath. Seven out of 19 children had one or two Rrs,FOT values excluded, and six children had three or four $R$ rs,FOT values excluded.

The mean values of spirometric indices did not vary significantly between 2 days or the 2 weeks, and the variation in these indices was mostly due to differences between the subjects. In contrast, the "within-subjects" proportion in the total variance was much larger in $R$ rs, FOT values, and this result did not change by application of the reliability index. This might have been due to the higher overall sensitivity of $R \mathrm{rs}$,FOT to detect functional changes both in the upper and lower respiratory tracts due to pollen season among these symptomatic children. A contribution of the pollen season was suggested by the fact that the CoV of day-to-day variation was larger in the first week, when the pollen counts were higher, than in the second week.

In the exercise challenge test the maximal relative changes were largest in $R$ rs,FOT. In addition, the ratio of the mean maximal relative change to the $\mathrm{CoV}$ of the baseline measurements was largest in Rrs,FOT, implying that it was the most sensitive index for the detection of functional changes in the exercise challenge test. However, the mean change from baseline $R$ rs,FOT values was not statistically significant due to large between-subject variation in responses. There were two children with $20 \%$ reductions in $R$ rs,FOT after the exercise. When these two children were excluded, the mean change in $R \mathrm{rs}$,FOT was statistically significant, and the mean (SD) of the maximal relative changes in $R$ rs, FOT was 19 (24)\%, (range $-0.1-74 \%)$. Previous studies have shown that FOT can also be used successfully in bronchial challenge tests using histamine, methacholine and allergens in children [5, 20, 22, 23, 26]. However WILSON et al. [24] found that in a methacholine test FOT was unreliable compared to the measurement of transcutaneous oxygen tension in 5 year old children.

The calculation of $\mathrm{CoV}$ is widely-used to describe the repeatability of measurements. Therefore, we also used 
it. This method is valid if the standard deviation is proportional to the mean. In the present data, the differences in the repeated measurements of the spirometric parameters were not proportional to the mean. Our $R$ rs,FOT data were rather more suggestive of a proportional model. However, we used an absolute rather than an proportional difference as the reliability index in order to control the quality of the measurements: firstly, because the difference was not clearly proportional to the mean; and secondly, in dynamic measurement situations, such as bronchial challenge tests, where the response changes fast with time, this index can be applied immediately to detect the maximal response within the limits of accepted variability.

In conclusion, measurement of respiratory resistance by means of the forced oscillation technique requires only passive co-operation, and it is, therefore, well-suited for measurements among children. The variation in $R$ rs,FOT values was larger than that of most spirometric indices. However, when a reliability index was applied. the immediate variation in $R$ rs,FOT values was comparable to those of MEF50 and MMEF. Rrs,FOT was the most sensitive parameter in the exercise challenge test, and therefore it appears to be suitable for detection of short-term functional changes in the respiratory system. However, the relatively low repeatability of $R$ rs,FOT over days and weeks may limit its applicability to longerterm follow-ups.

\section{References}

1. Quanjer $\mathrm{PhH}$, Tammeling GJ, Cotes JE, et al. Lung volumes and forced ventilatory flows. Report Working Party, Standardization of lung function tests. European Coal and Steel Community. Official statement of the European Respiratory Society. Eur Respir J 1993; 6 (Suppl. 16): 5-40.

2. Orehek J, Nicoli MM, Delpierre NS, Beaupré A. Influence of the previous deep inspiration in the spirometric measurements of provoked bronchoconstriction in asthma. Am Rev Respir Dis 1981; 123: 569-572.

3. DuBois AB, Brody AW, Lewis DH, Burgess BF. Oscillation mechanics of lungs and chest in man. J Appl Physiol 1956; 8: 587-594.

4. Desager K, Van Bever H, Làndsér F, et al. Use of the forced oscillation technique in infants. Eur Respir J 1991; 4: 248.

5. Mansell A, Levison H, Kruger K, Tripp TL. Measurement of respiratory resistance in children by forced oscillations. Am Rev Respir Dis 1972; 106: 710-714.

6. Duiverman EJ, Neijens HJ, van der Snee-van Smaalen M, Kerrebijn KF. Comparison of forced oscillometry and forced expirations for measuring dose-related responses to inhaled methacholine in asthmatic children. Bull Eur Physiopathol Respir 1986; 22: 433-436.

7. Lebecque P, Desmond K, Swartebroeckx Y, et al. Measurement of respiratory system resistance by forced oscillation in normal children: a comparison with spirometric values. Pediatr Pulmonol 1991; 10: 117-122.

8. Cuijpers CEJ, Wesseling G, Swaen GMH, Wouters EFM. Frequency dependence of oscillatory resistance in healthy primary school children. Respiration 1993; 60: 149-154.

9. Peslin R, Felicio da Silva J, Duvivier C, Chabot F. Respiratory mechanics studied by forced oscillations (during artificial ventilation. Eur Respir J 1993; 6: 772-784.
10. Van de Woestijne KP. The forced oscillation technique in intubated, mechanically-ventilated patients. Eur Respir J 1993; 6: 767-769.

11. Van de Woestijne KP, Desager KN, Duiverman EJ, Marchal F. Recommendations for measurement of respiratory input impedance by means of the forced oscillation method. Eur Respir Rev 1994; 4: 235-237.

12. Pleger E, Wilke A, Glaser Th, Müller E, Vogel J. Praktische Erfahrungen mit zwei oszillatorischen Meßverfahren, Siregnost FD \% und custo vit, zur Beurteilung chronischer Atemwegsobstruktionen. Pneumologie 1989; 43: 353-357.

13. Simm F. Polyfrequente oszillatorische Messung Des Atemwiderstandes einschießlich zugehörigem Phasenwinkel. Pneumologie 1989; 43: 376-381.

14. Sixt R, Aronsson PH, Solymar L. The forced oscillation technique in children, with special reference to use of low frequencies. Eur Respir Rev 1991; 1 (3): 222-225.

15. Sterk PJ, Fabbri LM, Quanjer PhH, et al. Airway responsiveness: standardized challenge testing with pharmacological, physical and sensitizing stimuli in adults. Report Working Party, Standardization of lung function tests. European Coal and Steel Community. Official statement of the European Respiratory Society. Eur Respir J 1993; 6 (Suppl. 16): 53-83.

16. SAS Institute Inc., SAS/STAT® User's Guide. Version 6. 4th Edn. Volume 1-2. Cary, NC, SAS Institute Inc., 1989.

17. Bland M. In: An Introduction to Medical Statistics. Oxford, Oxford University Press, 1988.

18. Lebecque P, Kiakulanda P, Coates AL. Spirometry in the asthmatic child: is FEF25-75 a more sensitive test than FEV1/FVC? Pediatr Pulmonol 1993; 16: 19-22.

19. Làndsér FJ, Nagels J, Clément J, van de Woestijne KP. Errors in the measurements of total respiratory resistance and reactance by forced oscillations. Respir Physiol 1976; 28: 289-301.

20. Lebecque P, Spier S, Lapirre J-G, Lamarre A, et al. Histamine challenge test in children using forced oscillation to measure total respiratory resistance. Chest 1987; 92: 313-318.

21. Lebecque P, Desmond K, Swartebroeckx Y, et al. Measurement of respiratory system resistance by forced oscillation in normal children: a comparison with spirometric values. Pediatr Pulmonol 1991; 10: 117-122.

22. Holmgren D, Engström I, Bjure I, Sixt R, Åberg N. Respiratory resistance and transcutaneous $\mathrm{PO}_{2}$ during histamine provocation in children with bronchial asthma. Pediatr Pulmonol 1993; 15: 168-174.

23. Solymar L, Aronsson P-H, Engström L, Bake B. Bjure J. Forced oscillation technique and maximum expiratory flows in bronchial provocation tests in children. Eur Respir Dis 1984; 65: 486-495.

24. Wilson NM, Bridge P, Phagoo SB, Silverman M. The measurement of methacholine responsiveness in 5 year old children: three methods compared. Eur Respir J 1995; 8: 364-370.

25. Gimeno F, van der Weele Th, Koëter GH, de Monchy JGR, van Altena R. Variability of forced oscillation (Siemens Siregnost FD5) measurements in patients and healthy subjects. Ann Allergy 1993; 71: 56-60.

26. Duiverman EJ, Neijens HJ, van Strik R, van der Sneevan Smaalen M, Kerrebijn KF. Bronchial responsiveness in asthmatic children aged 3 to 8 years measured by forced pseudorandom noise oscillometry. Bull Eur Physiopathol Respir 1986; 22: 27-34. 